\title{
Food Delivery Platforms During the COVID-19 Pandemic
}

\author{
Vera Amicarelli ${ }^{1}$, Giovanni Lagioia ${ }^{2}$, Rodica Pamfilie ${ }^{3}$, Raluca Mariana Grosu ${ }^{4}$ and \\ Christian Bux ${ }^{5}$ \\ 1)2)5) University of Bari Aldo Moro, Bari, Italy \\ 3)4) The Bucharest University of Economic Studies, Bucharest, Romania \\ E-mail: vera.amicarelli@uniba.it; E-mail: giovanni.lagioia@uniba.it; \\ E-mail: rodica.pamfilie@com.ase.ro; E-mail: raluca.petrescu@com.ase.ro; \\ E-mail: christian.bux@uniba.it
}

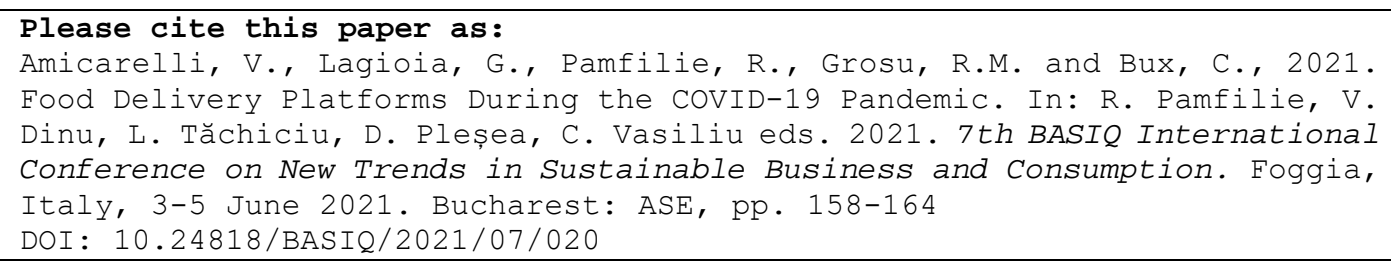

\begin{abstract}
The food delivery service represents one of the best options to make food available (quite) wherever it is required and, during the Covid-19 pandemic, this has played a fundamental role in everyday life. Among others, one of the main advantages of food delivery services was to conciliate social restriction, final consumption and food supply, allowing consumers to easily receive their meals and restaurants to withstand the economic crisis caused by the pandemic. Using data from the websites of the most used food delivery companies in Italy, as well as from official reports and market studies, the present exploratory study is developed on a qualitative approach. Envisaging the most used food delivery platforms in Italy, the aim of this work is to discuss their main features and figures, focusing on their impact on food consumption behaviors and economic sustainability during the Covid-19 pandemic. The preliminary results of our qualitative content analysis illustrate mainly positive facts specific to the food delivery service in Italy; the pandemic has provided new opportunities for companies, people and the entire economy, highlighting reactivity and readiness to change as the key-variables to survive in the market. In addition, it emerged that the lockdown period has accelerated food delivery businesses like never before, guaranteeing resilience to the businesses/restaurants-consumers-couriers triangle. Since limited investigations have been destined to the role of food delivery platforms during the pandemic, this research brings novel insights in the area, highlighting the role of Covid-19 as a driver for developing new strategies for businesses active in the food services area.
\end{abstract}

\section{Keywords}

Food delivery, mobile commerce, food waste, Covid-19 pandemic

DOI: $10.24818 / B A S I Q / 2021 / 07 / 020$

\section{Introduction}

Food delivery service (FDS) represents one of the best options to make food available (quite) wherever it is required, and during the Covid-19 pandemic it has played a fundamental role in everyday life. Indeed, one of the main advantages of FDS was to conciliate social restriction, final consumption and food supply, allowing consumers to easily receive their meals and restaurants to withstand the economic crisis caused by the pandemic. FDS does not represent a novel way to understand business and food consumption activities. Immediately after the Second World War, in a context of limited possibility for everyone to buy and to prepare their own meals at home, a Women's Volunteer Service started to deliver meals to ordinary citizens affected by war consequences. This rudimentary form of business started from Great Britain and then moved to the United States and Australia, in a continuous growth which invested first restaurants, and then the so-called Ho.Re.Ca. sector (Caratù, 2018). Over 
time, FDS has shown a good level of adaptability to change lifestyle and food consumption habits and, from the supply side, an interesting chance to enlarge business opportunities. Moreover, the introduction of mobile and smart technologies has deeply influenced the online FDS' offer, conquering new and increasing market shares.

It was estimated that, in Italy in 2018, among over 11 million people ordered by "telephone" or "in person" their meals, and only more than 4 million did it through online tools or digital apps (Privitera, 2019). However, these figures have been completely changed by the Covid-19 pandemic, considering its social and economic consequences. As well known, on the $11^{\text {th }}$ of March 2020, the World Health Organization has declared the novel COVID-19 outbreak as a global pandemic and, in the attempt to limit and contain the spread of the disease, many countries have adopted lockdown strategies. From the $8^{\text {th }}$ of March 2020 to the $3^{\text {rd }}$ of May 2020, Italy has been the first Western country to implement severe lockdown measures forcing people to stay at home, imposing smart working and smart learning, closing all non-essential commercial activities and allowing a very limited range of activities. In the range of a few days, Italian lifestyle has been totally modified. In the field of food consumption habits, more than $35 \%$ of Italians who regularly consumed meal out-of-home before the lockdown had to adapt their habits (Ismea, 2020). In general, people have been forced to stay at home, reducing as much as possible the frequency of shopping occasions, buying a little more than usual in supermarkets and preparing and consuming home-prepared meals (Amicarelli and Bux, 2021). Consequently, all retail activities and particularly restaurant and coffee-shops had to switch toward more versatile and digital meal offerings, to ensure their access for all groups of consumers. In this situation, digital (web and apps) FDSs have played a fundamental role in changing the approach among final consumers. In the pre-pandemic period, the majority of Italian consumers considered online FDS as a new exciting experience, and the possibility to receive a particular meal (e.g., vegan, Chinese) as a solution to improve time management (Coldiretti, 2018). During the lockdown, on the contrary, FDS has been considered as the best self-protective behavior (contactless delivery) or the most resilient solution to receive food in the safest way, satisfying at the same time government rules and eating needs. Therefore, as a consequence of the pandemic, among the different sales channels, the e-commerce increased by $160 \%$ and the Italian online purchases in the "food and grocery" sector has been estimated in more than 2.7 billion euros, with a growth of $70 \%$, of which FDS accounts for more than 700 million euro with a growth of $19 \%$ compared to 2019 results (Cavallo, Sacchi and Canfora, 2020; ZeroUno, 2020). In the light of these premises and considering that during 2020 the FDSs played a decisive role in redesigning retail-to-consumers interactions to address the crisis in the post-pandemic retail sector, the aim of this work is to discuss the impact of Covid-19 pandemic and the role of mobile commerce in the FDS. The analysis is based on the most used food delivery apps (FDAs) in Italy and discusses their main features and figures, focusing on their impacts on food consumption behaviors and economic sustainability.

\section{Literature review}

In recent years, scholars have been widely interested in FDS. Several authors have investigated FDSs' role in everyday life, examining the motives and reasons behind their use among people (Saad, 2020), while others have analyzed their impact on restaurant sales (Collins, 2020). However, there are limited investigations available in the FDS segment during the Covid-19 pandemic (Chang and Mayrhoefer, 2020), and research should focus on how technologies and food delivery could restore the entire food services, especially in the European Union (EU-27). Niu, et al. (2021) have analyzed the issue under the sustainable perspective, highlighting the potential of FDSs in the field of environment protection. Indeed, analyzing the difference between "Platform-to-Consumer Delivery" and "Restaurant-toConsumer Delivery", it emerged that logistic platforms are more environmentally friendly in times of intense market functioning, as during the pandemic. On the behavioral side, Dsouza and Sharma (2020) have estimated consumer behavior and expectation changes during the pandemic, highlighting as main driver for customers' satisfaction the need for food quality, as well as the respect for safety measures adopted either by restaurants or riders. Significant insights have underlined the role of Covid-19 as a driver for developing new strategies for business and customer retention in the future (Mehrolia, et al., 2020). 


\section{Materials and methods}

The present research aims to investigate FDAs main features and figures, focusing on their impacts on food consumer behaviors and economic sustainability. According to Statista (2020), the authors intend digital (or smart) food delivery as a service solution for prepared (or pre-portioned) meals, distinguishing between: (i) Restaurant-to-Consumer Delivery segment, which presupposes that the restaurant carries out directly the delivery of meals; and (ii) Platform-to-Consumer Delivery segment, which offers services of delivery from partner restaurants not caring directly the delivery themselves. Further, digital food delivery includes services which deliver prepared meals and other food for direct consumption only via apps or websites, not accounting non-processed or non-prepared food or phone orders. In terms of boundaries, the analysis of FDAs during the Covid-19 pandemic has regarded the Italian experience. Not by chance, Italy represents the first country in the EU-27 to discover the first official Covid-19 case and to react to the pandemic, prohibiting all movements of people and closing all non-essential business activities. Moreover, the Italian online food delivery revenues have been estimated at 844 million euro in 2021, while its users have reached the amount of approximately 12 million, representing more than $6 \%$ of whole EU-27 users (194 million people) (Statista, 2020). The analysis has been managed according to a qualitative and explorative approach, and data have been collected/observed from websites of food delivery companies, official reports and market studies (Privitera, 2020). Then, data interpretation has been conducted according to a qualitative content analysis (QCA). All the gathered information read word by word to capture key facts and key concepts on food delivery, have been analyzed to explore "knowledge and understanding of the phenomenon under study" (Downe-Wamboldt, 1992). The investigation could be divided within two steps. First, in order to understand all FDAs available on smartphones, the authors have typed on the search bar of App Store and Google Play the following words: "food delivery", "food home", "food take away" (in Italian). This step has been essential to comprehend which food deliveries are distributed and concretely operate at national level. Among all FDAs, only those dealing with pre-portioned ready-to-eat meals (e.g., hamburgers, pizzas, sushi) have been selected, while those selling specific products (e.g., wine), offering the opportunity to online grocery or distributing more complex food services (e.g., catering or kitchen stuffs) have not been considered. Further, to understand the main search trends of such FDAs, the authors have analyzed their tendencies on Google Trends comparing each of them with the other competitors. The analysis was focused on Italy over the last year, from the 3rd of February 2020 (pre-pandemic period) to the 3rd of February 2021 (during-pandemic period). The investigated category has been "food and beverages". In the light of these comparisons, only the top five most sought FDAs have been taken into consideration for a subsequent qualitative analysis, being intended as an interesting sample to further investigate. The second step regarded the qualitative investigation of the FDAs. To comprehend and evaluate opportunities and main challenges of the FDAs, the authors have selected some useful criteria: (i) companies' information (e.g., year of foundation, capital, revenue); (ii) characteristics of the offer to consumers (e.g., payment method, traceability of the order, distance guaranteed by riders, average cost of delivery); and (iii) background/opportunities before and after the Covid-19 pandemic.

\section{Results and main findings}

It emerged from App Store and Google Play that a plethora of FDAs exist (e.g., Alfonsino, Cosaordino, Delivereat Italia, Deliveroo, etc.) and operate at national level. However, in the light of Google Trends results, only a few have registered a constant search throughout the year, with significant peaks in coincidence with the first Italian lock-down (from the $8^{\text {th }}-14^{\text {th }}$ of March 2020 to the $3^{\text {rd }}-9^{\text {th }}$ of May 2020). Figure no. 1 illustrates the top five FDAs in Italy pre- and during-pandemic and their related search trend. 


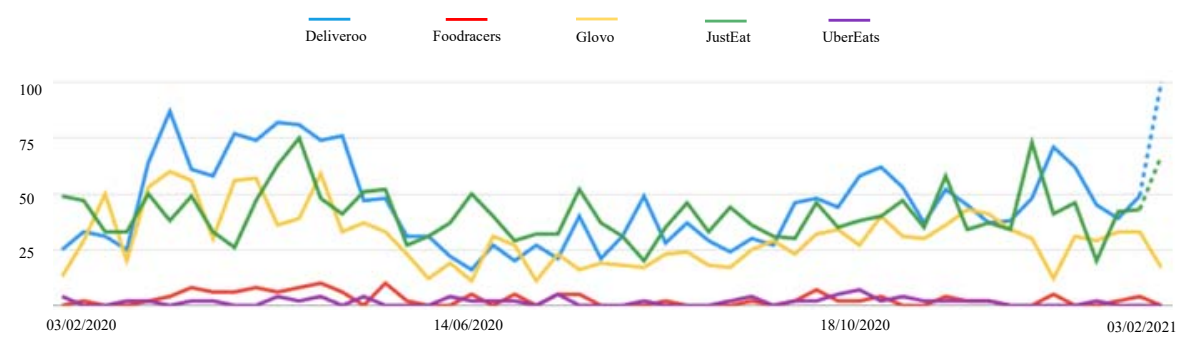

Figure no. 1. Top five FDAs search trend in Italy during the Covid-19 pandemic Source: Personal elaboration by the authors on Google Trends results

It emerged that the most clicked FDAs are: a) Deliveroo; b) Foodracers; c) Glovo; d) Just Eat; and e) Uber Eats. Over a year, Figure no. 1 shows that all five apps have reached their peaks during the first Italian lockdown but have also recorded a slight increase as soon as the Italian government has promulgated the decree (from the $3^{\text {rd }}$ of November 2020 onward) providing the division into four areas (red, orange, yellow and white) corresponding to different risk scenarios, for which specific restrictive measures have been foreseen. Further, to comprehend the variation between the pre-pandemic and during-pandemic trends, the authors have compared average FDAs results during the lockdown peak (from the $8^{\text {th }}$ of March 2020 to the $9^{\text {th }}$ of May 2020) with those registered in the same period, one year before (Figure no. 2). It is important to underline that the numbers (0-100) represent the search interest with respect to the highest point of the graph in terms of region, category and period, therefore they are not absolute scores. At a first glance, results show a sharp increase in all FDAs searches during the pandemic, highlighting a quite coherent and constant trend during the first Italian lockdown. Some FDAs, slightly and highly searched during the pandemic, seem not to exist only one year before (respectively, Foodracers and Glovo). Under a qualitative perspective, the sample of FDAs have been analyzed through official websites, reports (Pierre and Michaud, 2020; Just Eat, 2019; 2020), literature (Caratù, 2018; Privitera, 2019; Galati, et al., 2020) and market data (Statista, 2020) with regard to companies' information, characteristics of the offer to consumers and background/opportunities before and during the Covid-19 pandemic. As a common result, according to Just Eat (2020), it emerges a general growth trend for the entire Italian food delivery market, which nowadays represents between $20-25 \%$ of the entire home delivery service (18\% in 2019). Such growth has been recorded not only in large cities, but also in peripheral areas and provinces.

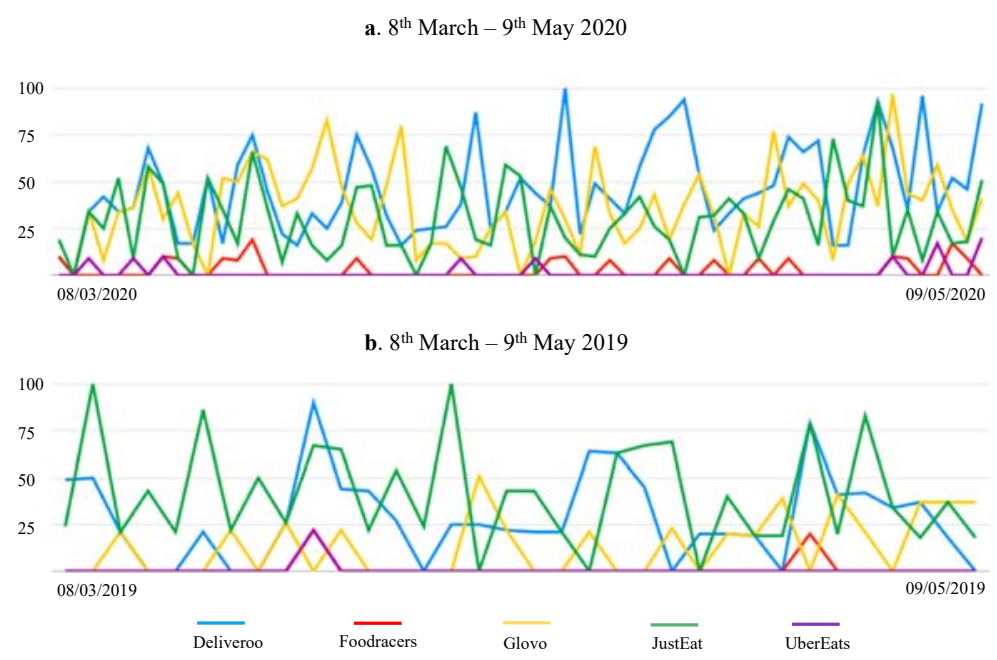

Figure no. 2. Top five FDAs search trend before and during the Covid-19 pandemic Source: Personal elaboration by the authors on Google Trends results 
Table no. 1 illustrates the companies' characteristics and the main worldwide features, highlighting some Italian details. Of course, as the pandemic is still underway, official data updated to 2020 are still not available. Therefore, table no. 1 shows the highlights updated to 2019.

Table no. 1. Food delivery companies' main features (2019)

\begin{tabular}{|l|c|c|c|c|c|}
\hline \multirow{2}{*}{ Food delivery } & \multirow{2}{*}{ Year } & \multirow{2}{*}{ Headquarters } & \multicolumn{2}{|c|}{ Restaurants } & \multirow{2}{*}{ Couriers } \\
\cline { 4 - 5 } & & & Worldwide & Italy & \\
\hline Deliveroo & 2013 & London, UK & 80,000 & 13,000 & 60,000 \\
\hline Foodracers & 2015 & Treviso, Italy & 1,000 & 1,000 & 530 \\
\hline Glovo & 2015 & Barcellona, Spain & 66,000 & 5,000 & 59,000 \\
\hline Just Eat & 2000 & Kolding, Denmark & 53,000 & 10,000 & N/D \\
\hline Uber Eats & 2014 & San Francisco, USA & 220,000 & N/D & N/D \\
\hline
\end{tabular}

Source: developed by authors, based on Just Eat, 2019; Galati et al., 2020; Glovo, 2020; Uber Investor, 2020

It emerges from Italian facts that one of FDAs weaknesses is the distribution (capillarity) of the partner restaurants/couriers in the Italian country. Indeed, FDAs are mainly available in urban areas (e.g., Just Eat has reached over 900 cities, while Deliveroo barely exceeds 200 cities), therefore leading to an unequal distribution on the territory (Privitera, 2019). The delivery service in the suburbs is significantly lower, but still available in Northern Italy by Foodracers (55 cities distributed among EmiliaRomagna, Friuli Venezia Giulia, Veneto and Trentino-South Tyrol). However, it seems that the number of restaurants, due to the Covid-19 pandemic, has increased by approximately $30 \%$ compared to the previous year, justified by requests, five or six times higher (Just Eat, 2020). In terms of characteristics of the offer to consumers, all of these companies have either a desktop version (website) or a mobile one (app). According to the payment method, some FDAs allow the payment still with cash (sometimes depending on restaurants), while others require only the online payment (e.g., credit card, PayPal). Tendentially, digital payment has been estimated in $70 \%$ of total delivery payments, increasing at a rate of $36 \%$ only in 2020 (Just Eat, 2020). Moreover, several differences emerged in terms of delivery costs, registered on average between 2-5 euro. In reference to this, Deliveroo calculates delivery rates according to: a) distance between restaurants and consumers; b) service charges, intended as customercare offered 24 hours a day, 7 days a week; c) additional supplement, added if the minimum expense indicated by the restaurant is not reached by the consumer. Likewise, some FDAs give the chance to leave a tip to the restaurant to encourage its activity. In addition, some FDAs offer the premium version, which eliminate delivery costs for each order for a fixed monthly cost. Table no. 2 summarizes the main previously mentioned highlights from the qualitative investigation.

Table no. 2. FDAs main highlights from the qualitative investigation

\begin{tabular}{|c|c|c|c|c|c|c|}
\hline \multirow{2}{*}{ FDAs } & \multicolumn{2}{|c|}{ Version } & \multicolumn{2}{|c|}{ Payment method } & \multirow{2}{*}{$\begin{array}{l}\text { Average deliv- } \\
\text { ery costs }\end{array}$} & \multirow{2}{*}{$\begin{array}{c}\text { Premium version } \\
\text { (plus, prime, pass) }\end{array}$} \\
\hline & Website & Mobile & Cash & Online & & \\
\hline Deliveroo & X & $\mathrm{X}$ & $\mathrm{X}$ & $\mathrm{X}$ & $1-2.50 €$ & $12.99 € /$ month \\
\hline Foodracers & $\mathrm{X}$ & $\mathrm{X}$ & $\mathrm{X}$ & $\mathrm{X}$ & $2-5 €$ & \\
\hline Glovo & $X$ & $X$ & $\mathrm{X}$ & $X$ & $2.50-3.90 €$ & $7.99 € /$ month \\
\hline Just Eat & $\mathrm{X}$ & $\mathrm{X}$ & $\mathrm{X}$ & $\mathrm{X}$ & $1-2 €$ & \\
\hline Uber Eats & $X$ & $\mathrm{X}$ & & $X$ & $1-2 €$ & $9.99 € /$ month \\
\hline
\end{tabular}

In terms of company values, all declare their attention toward sustainability and environmental issues. For instance, Just Eat states that "It's time for a positive change. Whether it's our 100\% compostable takeaway boxes, our commitment to reducing food waste, or low-carbon electric powered deliveries, we want to make a difference" (Just Eat, 2020), while Deliveroo has introduced the idea of electromobility for home delivery (Galati et al., 2020). Moreover, Deliveroo asks consumers whether cutleries are needed or not, calling for help to reduce waste. Lastly, it is crucial to underline that some apps have a section devoted to users' safety and health during the Covid-19 pandemic. As instance, updated on 
the 1st of April 2020, Uber Eats app suggests a few options to ensure safety to the entire community either to consumers (e.g., "leave at the door" delivery) or to restaurants (e.g., best practices as sealing meals against tampering, disinfection and cleaning).

\section{Conclusions}

The Covid-19 pandemic, among other health and social challenges, has dangerously affected the economy and all sectors, from agriculture to food consumption, impacting both sides of the food services to high degrees (Amicarelli and Bux, 2021). However, despite the pandemic being defined as the worst world crisis after the Second World War, it has offered several new opportunities for companies, people and the entire economy, highlighting reactivity and readiness to change as the key-variables to survive in the market. Lockdown has accelerated the home delivery business like never before, and positive effects of the pandemic to food delivery have been reached on three sides of the business model as follows: (i) businesses/restaurants, which have even generated extra revenues in their digital channel; (ii) consumers, who had the chance to receive their food directly at home without running the risk of contagion; (iii) couriers, that made earning through flexible jobs (Pierre and Michaud, 2020). On the side of consumers, general advantages offered by FDAs regard the convenience of having meals readyto-eat in a short time, the chance to choose the restaurants they like based on distance and offer, and the opportunity to check other users' reviews and restaurants' rankings already existing on the platform (e.g., Just Eat). In terms of payment, users could choose among different payment methods, from the most common cash to the online tools such as ApplePay. Moreover, in a safer way related to the pandemic, it has emerged the advantage of FDAs in terms of contactless food. Indeed, the only person that consumers meet are the couriers. On the business side, the advantage of adhering to the FDAs has consisted in increasing home sales and related revenues, without the need to hire staff and prepare tables (which, of course, is not always possible in the pandemic period). Through the usage of FDAs, the restaurants are able to publish their meals on virtual showcases, customizing the digital menu and making it more usable to customers. In addition, restaurants could choose the delivery times, the served areas and all promotional initiatives they want to advertise. Briefly, food delivery faced a sudden change during the Covid-19 pandemic. In some cases, the demand for online food products has even doubled, posing new business challenges previously neglected and putting under pressure the e-commerce and the mobile commerce players. Despite the background of Italian consumers - previously not accustomed to digital commerce - the mix of lockdown, the new needs and the new fears generated by the pandemic have imposed to users the use of digital commerce and digital payments, at the same time convincing the entrepreneurs active in the restaurant area of the need to enhance the online offer. To enhance the economy, allowing companies to resist and consumers to be fully satisfied, it is necessary that the positive growth during the pandemic persists over time.

\section{References}

Amicarelli, V. and Bux, C., 2021. Food waste in Italian households during the Covid-19 pandemic: a self-reporting approach. Food Security, 13, pp.25-37.

Caratù, M., 2018. Il fenomeno del Food Delivery, Rapporto Italia 2018. Eurispes, 30, pp.935-947.

Cavallo, C., Sacchi, G., Carfora, V., 2020. Resilience effects in food consumption behaviour at the time of Covid-19: perspectives from Italy. Heliyon, 6(12), Article number: 05676.

Chang, H.H. and Meyerhoefer, C.D., 2021. COVID-19 and the Demand for Online Food Shopping Services: Empirical Evidence from Taiwan. Americam Journal of Agricultural Economics, Aheadof-print.

Coldiretti, 2018. Consumi, cibo dal web per 1 italiano su 3 (+47\%), [online] Available at: $<$ https:/www.coldiretti.it/economia/consumi-cibo-dal-web-1-italiano-3-47> [Accessed 10 February 2021].

Collins, J., 2020. The Impact of Online Food Delivery Services on Restaurant Sales, Department of Economics, Stanford University. [online] Available at: $<$ https://web.stanford.edu/ leinav/teaching/Collison.pdf $>$ [Accessed 8 February 2021]. 
Downe-Wamboldt, B., 1992. Content analysis: method, applications, and issues. Health Care for Women International, 13, pp.313-321.

Dsouza, D. and Sharma, D., 2020. Online food delivery portals during COVID-19 times: an analysis of changing consumer behavior and expectations. International Journal of Innovation Science, 13(2), pp.218-232.

Galati, A., Crescimanno, M., Vrontis, D. and Siggia, D., 2020. Contribution to the Sustainability Challenges of the Food-Delivery Sector: Finding from the Deliveroo Italy Case Study. Sustainability, 12, Article number: 7045.

Glovo, 2020. About us, [online] Available at: <https://about.glovoapp.com/en/> [Accessed 4 February 2021].

ISMEA, 2020. Emergenza COVID-19 Rapporto sulla domanda e l'offerta dei prodotti alimentari nelle prime settimane di diffusione del virus, 1-2-3, Rome.

Just Eat, 2019. La mappa del cibo a domicilio in Italia 2019, [online] Available at: $<$ https://www.justeat.it/esplora/osservatorio2019> [Accessed 4 February 2021].

Just Eat, 2020. La mappa del cibo a domicilio in Italia. Osservatorio nazionale sul mercato del cibo a domicilio online in Italia 2020, Quarta edizione, [online] Available at: <https://www.justeat.it [Accessed 4 February 2021].

Mehrolia, S., Alagarsamy, S. and Solaikutty, V.M., 2020. Customers response to online food delivery services during COVID-19 outbreak using binary logistic regression. International Journal of Consumer Studies, 45, pp. 396-408.

Niu, B., Li, Q., Mu, Z., Chen, L. and Ji, P., 2021. Platform logistics or self-logistics? Restaurants' cooperation with online food-delivery platform considering profitability and sustainability. International Journal of Production Economics, 234, 108064.

Pierre, O. and Michaud, S., 2020. Letter to Glovo's shareowners. [online] Available at: $<$ https://about.glovoapp.com/en/inside-glovo/letter-glovo-shareowners/> [Accessed 4 February 2021].

Privitera, D., 2019. Digital food delivery e innovazioni di servizio. Una valutazione virtuale. AGEIGeotema, Anno XXIII, gennaio-aprile, 59, pp.91-98.

Saad, A.T., 2020. Factors affecting online food delivery service in Bangladesh: an empirical study. British Food Journal, 123, pp.535-550.

Statista, 2020. Online Food Delivery, [online] Available at: < https://www.statista.com/outlook/374/141/online-food-delivery/italy> [Accessed 4 February 2021].

Takeaway.com, 2020. Full Year 2019 Results, Amsterdam, 13 February 2020. [pdf] Available at: https://www.rns-pdf.londonstockexchange.com/rns/8345C_1-2020-2-12.pdf [Accessed 4 February 2021].

Uber Investor, 2020. Uber Announces Results for Second Quarter 2020, [online] Available at: $<$ https://investor.uber.com/news-events/news/press-release-details/2020/Uber-Announces-Results-for-Second-Quarter-2020/default.aspx $>$ [Accessed 4 February 2021].

ZeroUno, 2020. Osservatorio eCommerce B2C 2020, come sono andati gli acquisti online in Italia? [online] Available at: <https://www.zerounoweb.it/trends/dinamiche-di-mercato/osservatorioecommerce-b2c-2020-come-sono-andati-gli-acquisti-online-in-italia/> [Accessed 10 February 2021]. 